\title{
Aerobic exercise in major psychiatric disorders: promises and challenges
}

\author{
Andrea Schmitt $^{1} \cdot$ Peter Falkai $^{1}$
}

Published online: 4 February 2017

(C) Springer-Verlag Berlin Heidelberg 2017

Cognitive deficits, specifically in episodic and working memory, and structural deficits like hippocampal volume reduction are hallmarks of an unfavorable outcome in schizophrenia and affective disorders. These features develop early in the course of the illness and cognitive deficits are difficult to treat with current pharmaceutical options. Recent evidence suggests that volume reduction in the hippocampus correlates with episodic memory deficits in schizophrenia [1]. Aerobic exercise comprising endurance training alone or in combination with cognitive training was demonstrated to increase hippocampal volume, $N$-acetyl-aspartate/creatinine ratio, to improve episodic memory in schizophrenia patients and working memory in major depression [2-4] and thus is promising to contribute to recovery. However, our subsequent study in a larger cohort of chronic schizophrenia patients that combined endurance training with cognitive remediation for a period of 3 months did not replicate hippocampal findings, but found the volume of the left temporal cortex to be increased [5].

The questions which disease-related environmental or genetic factors may inhibit neuroplastic changes in the hippocampus or other brain regions during aerobic exercise and impact on severity of neuropsychological deficits in individual patients need to be answered. In addition, other neurobiological mechanisms of aerobic exercise, e.g., on neurogenesis, neurotransmitter systems and stressrelated hormones, have to be identified in major psychiatric

Andrea Schmitt

Andrea.Schmitt@med.uni-muenchen.de

Department of Psychiatry and Psychotherapy, Ludwig-

Maximilians-University Munich, Nußbaumstr. 7,

80336 Munich, Germany disorders. In this issue, Carneiro et al. report that in women with depression, add-on aerobic exercise had no effects on cortisol and monoamine levels [6]. Feasibility and physical adaptations to endurance training have been shown in patients with severe psychiatric disorders such as chronic schizophrenia. However, these patients did not show significant adaptations in energy metabolism measured as power at fixed levels of lactate concentrations. This reduced ability to increase efficiency of aerobic energy metabolism or reduced adaptation potential may be explained by impaired functions of mitochondria [7]. A meta-analysis of exercise interventions in schizophrenia indicated that improvement of symptoms occurs with a higher intensity of training [8]. However, the optimal training intensity and duration of training in major psychiatric disorders are yet to be defined. In a small group of patients with different psychiatric diagnoses that included schizophrenia patients, a short period of an 8-week high-intensity interval training did not decrease psychopathological symptoms, but increased physical fitness and improved anxiety [9]. High-intensity training may have a higher potency than conventional endurance training to improve cognitive deficits, negative symptoms and metabolic parameters in major psychiatric disorders, but neuroplastic changes in the brain need to be identified. In addition, benefits of muscle strength training on neurocognition have not been investigated, but first results indicate improvements of mood and anxiety [10] and thus positive effects on symptom severity are to be expected. Future studies will disentangle mode and intensity of add-on aerobic exercise training needed to improve recovery in major psychiatric disorders. 


\section{References}

1. Hasan A Wobrock T, Falkai P, Schneider-Axmann T, Guse B, Backens M, Ecker UK, Heimes J, Galea JM, Gruber O, Scherk $\mathrm{H}$ (2014) Hippocampal intergrity and neurocognition in firstepisode schizophrenia: a multidimensional study. World J Biol Psychiatry 15(3):188-199

2. Pajonk FG, Wobrock T, Gruber O, Scherk H, Berner D, Kaizl I, Kierer A, Müller S, Oest M, Meyer T, Backens M, SchneiderAxmann T, Thornton AE, Honer WG, Falkai P (2010) Hippocampal plasticity in response to exercise in schizophrenia. Arch Gen Psychiatry 67(2):133-143

3. Oertel-Knöchel V, Mehler P, Thiel C, Steinbrecher K, Malchow B, Tesky V, Ademmer K, Prvulovic D, Banzer W, Zopf Y, Schmitt A, Hänsel F (2014) Effects of aerobic exercise on cognitive performance and individual psychopathology in depressive and schizophrenia patients. Eur Arch Psychiatry Clin Neurosci 264(7):589-604

4. Malchow B, Keller K, Hasan A, Dörfler S, Schneider-Axmann T, Hillmer-Vogel U, Honer WG, Schulze TG, Niklas A, Wobrock T, Schmitt A, Falkai P (2015) Effects of endurance training combined with cognitive remediation on everyday functioning, symptoms and cognition in multi-episode schizophrenia patients. Schizophr Bull 41(4):847-858

5. Malchow B, Keller K, Keeser D, Hasan A, Rauchmann B, Kimura H, Schneider-Axmann T, Dechent P, Ertl-Wagner B,
Honer WG, Hillmer-Vogel U, Schmitt A, Wobrock T, Niklas A, Falkai P (2016) Effects of aerobic exercise on structural plasticity in multi-episode schizophrenia. Schizophr Res 173(3):182-191

6. Carneiro LSF, Mota MP, Vieira-Coelho MA, Alves RC, Fonseca AM, Vasconcelos-Raposo J (2017) Monoamines and cortisol as potential mediators of the relationship between exercise and depressive symptoms. Eur Arch Psychiatry Clin Neurosci 1-5. doi:10.1007/s00406-016-0719-0

7. Keller-Varady K, Hasan A, Schneider-Axmann T, Hillmer-Vogel U, Adomßent B, Wobrock T, Schmitt A, Niklas A, Falkai P, Malchow B (2016) Training in schizophrenia patients and healthy subjects: differences and similarities. Eur Arch Psychiatry Clin Neurosci 266(5):461-473

8. Firth J, Cotter J, Elliott R, French P, Yung AR (2015) A systematic review and meta-analysis of exercise interventions in schizophrenia patients. Psychol Med 45(7):1343-1361

9. Heggelund J, Kleppe KD, Morken G, Vedul-Kjelsås E (2014) High aerobic intensity training and psychological States in patients with depression or schizophrenia Front Psychiatry $5: 148$.

10. Stanton R, Reaburn P, Happell B (2013) Is cardiovascular or resistance exercise better to treat patients with depression? A narrative review. Issues Ment Health Nurs 34:531-538 